\title{
PABSARENWID
}

\section{EL MAL EN LA SOCIEDAD ESPAÑOLA CONTEMPORÁNEA: EL CINE NEGRO DE ENRIQUE URBIZU}

\author{
María Pilar Rodríguez \\ Universidad de Deusto \\ maria.pilar@deusto.es
}

\begin{abstract}
RESUMEN: El artículo explora las características del cine negro de Enrique Urbizu a través de un análisis de la presencia del mal en la sociedad contemporánea proyectada en La caja 507 (2002) y No habrá paz para los malvados (2011). Partiendo de la teoría de la "banalidad del mal" desarrollada por Hanna Arendt en el primer caso y de las aportaciones de Jean Baudrillard and Zygmunt Bauman en el segundo, el texto recorre las dos películas para trazar la trayectoria del realizador, que representa un modo de hacer cine negro éticamente comprometido y responsable con el contexto social. La denuncia de un sistema corrupto e inoperante sirve de fondo para la exposición de un paisaje humano desolador donde solo la acción individual resulta efectiva.
\end{abstract}

PALABRAS CLAVE: Urbizu; cine negro; mal; compromiso ético; denuncia

ABSTRACT: This article explores the particular approach to film noir by Enrique Urbizu through an analysis of the presences of evil in contemporary Spanish society as projected in Box 507 (2002) and No rest for the wicked (2011). Based on the theory by Hanna Arendt on the "banality of evil" for the analysis of the first film and up readings of Jean Baudrillard and Zymungt Bauman for the second, this text studies the sense of ethical commitment and social responsibility in the works by Urbizu. The exposition of a corrupt and dysfunctional social system is 
the background for a desolated human landscape in which individual intervention is the only option.

Keywords: Urbizu; Film Noir; Evil; Ethical Commitment; Social Denunciation

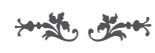

\section{BREVE CONTEXTUALIZACIÓN DEL GÉNERO}

La definición precisa del cine negro siempre ha sido una tarea que ha escapado a los esfuerzos llevados a cabo por investigadores, críticos y estudiosos de este género (o tal vez de este estilo, ya que ni siquiera en cuanto a su pertenencia a una u otra categoría existe un acuerdo). Andrew Spicer en Historical Dictionary of Film Noir revisa exhaustivamente la historia y el desarrollo del género y concluye que la falta de una caracterización rígida y estable ha sido una constante en su trayectoria. Señala que no existe un acuerdo acerca del corpus de películas que deban incluirse bajo la categoría de cine negro en ninguna de sus filmografías nacionales, ya que cada nuevo estudio ofrece títulos que no siempre coinciden. A esto hay que añadir, afirma, que el cine negro ha estado en continuo desarrollo y ha ido mutando y transformándose a lo largo del tiempo (2010: xxxvii). En sentido estricto, el cine negro clásico, afirma Spicer, responde al término acuñado en Francia por el crítico Nino Frank (film noir) el 26 de agosto de 1946 en su reseña de El halcón maltés (The Maltes Falcon, 1941), Perdición (Double Indemnity, 1944), Historia de un detective (Murder, My Sweet, 1944) y Laura (1944), para referirse a un grupo de películas americanas en blanco y negro realizadas entre 1940 y 1959. El crítico percibía en ellas "un nuevo modo de cine sobre el crimen con un estilo visual oscuro y amenazador, una narración compleja con voice-overs y flashbacks y un interés acusado por la psicología ambigua e incierta de los personajes"1 (Spicer 2010: xxxviii). A partir de entonces se ha designado "neo-noir" o "nuevo cine negro" a aquellas producciones que se fueron desarrollando a partir del período clásico (1940-1959).

En lo que hace referencia a las constantes que caracterizan a este tipo de cinematografía, Spicer ofrece un detallado compendio de rasgos clasificatorios que pueden agruparse en torno a ciertas categorías. En primer lugar se puede hablar de cine negro en función de un tono o estilo visual particular que emplea marcados contrastes de luces y sombras y composiciones asimétricas y descentradas desde la perspectiva de ángulos y movimientos de cámara poco convencionales y focalizaciones distorsionadas. Todo ello proporciona un sentido del espacio como amenaza y como trasposición clara del sentimiento de alienación que experimentan los protagonistas. En segundo lugar, cabe mencionar ciertos procedimientos narrativos tales como la presencia de un narrador múltiple, de la voice over y de las elipsis y flashbacks que rompen con las convenciones estricta-

\footnotetext{
1 "A new mode of crime film with a dark, brooding visual style, complex narration with voice-overs and flashbacks, and a marked interest in the characters' uncertain psychology". (Todas las traducciones en el texto son de la autora; se incluye el original en notas al pie).
} 
mente cronológicas y lineales del cine de Hollywood. Como resultado, en lugar de una estricta causalidad se percibe un sentimiento inconcluso de ambigüedad. En tercer lugar, es factible definir el cine negro en función de sus espacios y localizaciones y por la presencia de personajes arquetípicos:

La mayoría de las películas de cine negro se desarrollan en ciudades oscuras y nocturnas, con calles mojadas por la lluvia que reflejan las luces de neón y en las que un anti-héroe alienado y perturbado psicológicamente se encuentra con una femme fatale malvada que será su destrucción. ${ }^{2}$ (Spicer 2010: xl)

En tercer lugar, afirma Spicer, se puede unificar el cine negro por medio de un predominante tono oscuro, moralmente ambivalente que esconde un sentido de la existencia absurdo y desprovisto de sentido (Spicer 2010: xxxix-ix). Ninguno de estos tres acercamientos es concluyente, ni de modo independiente ni en sus diversas combinaciones, ya que siempre será posible encontrar excepciones y obras que escapen a esta o a otras caracterizaciones. Javier Sánchez Zapatero y María Marcos Ramos han llevado a cabo recientemente una minuciosa conceptualización de las características definitorias del cine negro $(2014,2015)$. En sus estudios, más allá de rasgos formales, estilísticos o estructurales -tales como la presencia de personajes estereotipados o prototípicos, el marco espacial urbano, las estructuras narrativas basadas en la investigación y en el suspense o la inserción de escenas de acción-, los autores privilegian como rasgo definitivo y definitorio del género una cosmovisión crítica y negativa del mundo. A partir de las aportaciones de José Luis Sánchez Noriega, Carlos Heredero, Román Gubern y Antonio Santamarina, entre otros, Sánchez y Marcos subrayan la constante aparición de un dualismo entre la aparente visión conformista de la sociedad y una indagación más profunda que refleja un diagnóstico moral cargado de pesimismo. Tal será igualmente el punto de partida que el presente trabajo adopte para su indagación en las dos películas seleccionadas, ya que Enrique Urbizu elige como tema en estas dos obras la articulación del mal en la sociedad española a través de dos tramas ligadas principalmente a la corrupción moral y política en La caja 507 y al terrorismo en No habrá paz para los malvados. En sus películas y en sus declaraciones, el director se decanta por una visión del género en la que el mal corrompe al sistema en todos sus estamentos y en una variedad de ramificaciones, de modo que sus tentáculos se extienden de modo implacable y sin redención posible, como de expondrá con detalle en el análisis de ambas obras.

Para concluir este apartado, basten unos brevísimos apuntes acerca del camino recorrido por el cine negro en España. Ann Davies señala que las primeras décadas de la dictadura franquista (1940 y 1950) fueron los años más duros de la represión y coincidieron con el auge del cine negro en Estados Unidos (2009: 15). Como apuntan Sánchez Zapatero y Marcos Ramos, existieron una

\footnotetext{
2 "Most noirs take place in dark, nighttime cities, their streets damp with rain that reflects the flashing neon signs where the alienated, often psychologically disturbed, male antihero encounters a deceitful femme fatale leading to his doom".
} 
serie de razones ligadas a la inexistencia de una tradición literaria nacional vinculada a la novela negra y a la presencia de la censura, que impidieron que el cine negro tuviera un desarrollo similar al de otros países europeos, como Francia o Italia, si bien señalan algunas obras películas anteriores que comparten rasgos del cine negro. Elena Medina, sin embargo, en su libro Cine negro y policíaco español de los años cincuenta estudia las producciones nacionales de esta década y detalla los criterios que regían en la aplicación de la censura y los rasgos propios y característicos del cine negro y policíaco español. Desde 1950, con películas como Apartado de correos 1001 (Julio Salvador) o Brigada criminal (Ignacio Iquino), ya es posible recoger ejemplos de representaciones de la realidad urbana, en este caso barcelonesa con influencias del neorrealismo italiano. Del mismo modo Spicer incluye una veintena de títulos en su lista de la filmografía española de cine negro anterior a 1975. Sin embargo, Rob Stone se muestra tajante en su negativa a admitir la presencia del cine negro en España antes de la muerte de Franco: "No existe tal como el cine negro español. Al menos no lo hay hasta la muerte del General Franco en 1975. Durante los cuarenta años de la dictadura fascista el cine negro era una bestia negra, incapaz de mostrar su cara por miedo a las represalias"3 (2007: 185). Spicer insiste en la opresión de la dictadura y añade el predominio del mundo rural y la rigidez del catolicismo como elementos disuasorios del desarrollo de un cine negro español, y añade: "España carecía de una tradición de novela negra propia; tampoco abundaban las traducciones de obras norteamericanas, y las películas americanas se consideraban con sospecha"4 (2010: 284). Incluso Elena Medina admite que la ambigüedad moral propia del género negro no podía darse realmente en una época en la que el régimen franquista y la censura no podían permitir que se desdibujaran los límites entre el bien y el mal, y concluye: "el desenmascaramiento del culpable tenía que ser claro y rotundo porque, en nuestro cine, el criminal siempre la paga" (2000: 15). Sánchez Zapatero y Marcos Ramos igualmente señalan que, si bien en las cintas anteriores a 1975 es posible encontrar elementos que remiten a los clásicos estadounidenses, esas películas en el fondo no hacen sino reforzar algunos de los principios estables del régimen franquista tales como la fortaleza de los cuerpos policiales o la imagen de seguridad de España frente al enemigo externo (2014: 6-7). Tanto Stone como Spicer afirman que el primer ejemplo palpable de cine negro español es la película de Juan Antonio Bardem Muerte de un ciclista (1955). Por su parte, Francesc Sánchez Barba analiza de modo exhaustivo las películas españolas durante la etapa franquista dentro del término "cine negro español", que se aparta de otros modelos por su obligación de estar sometido a una férrea censura moral. ${ }^{5} \mathrm{Si}$, como vemos, existe entre la crítica un acuerdo

\footnotetext{
3 "There is no such thing as Spanish film noir. At least there is none to speak of until after the death of General Franco in 1975. During the forty years of the fascist dictatorship film noir was a bête noir unable to show its face for fear of reprisals on its perpetrators".

4 "Spain lacked a tradition of indigenous hard-boiled crime fiction, or even American translations, and American films were treated with suspicion".

${ }^{5}$ Agrupa las películas estudiadas en dos períodos: 1950-1957 y 1958-1965, con una serie de rasgos caracterizadores que el autor detalla con gran acierto (2007: 81-84).
} 
en que tras la muerte de Franco se hizo posible la irrupción de una corriente de nuevo cine negro en España, en parte impulsado por el boom de la novela negra, con Manuel Vázquez Montalbán o Andreu Martín como algunos de sus principales representantes, es a partir de la década de los noventa cuando, como señalan Sánchez Zapatero y Marcos Ramos, "parece detectarse un mayor interés de los directores nacionales por utilizar un cine negro como vehículo para establecer miradas críticas sobre la realidad circundante y denunciar las diferentes formas, tanto directas como latentes, a través de las que la violencia se manifiesta en la realidad actual" (2014: 7). En las últimas décadas el realizador Enrique Urbizu ha sido quien con mayor asiduidad y de modo más certero ha utilizado los recursos narrativos, expresivos y formales del cine negro para la elaboración de sus películas. Varios son los críticos que reconocen al realizador vasco como el representante más significativo de este género en la cinematografía española (Sánchez Zapatero \& Marcos Ramos 2014; Alarcón 2011; Heredero \& Santamarina 2003). A las películas claramente inscritas en el género, Todo por la pasta (2001), La caja 507 y No habrá paz para los malvados se añaden otras que participan de ciertos rasgos del cine negro tales como Cachito (1996) y La vida mancha (2003). El análisis de las dos películas seleccionadas propone una caracterización del modo de desarrollar el género del cine negro por parte del realizador vasco en la que subyace el compromiso ético y la responsabilidad social en su exposición de una sociedad corrupta y marcada por el mal endémico que afecta a todas las capas del sistema.

\section{Frágiles VOLUNTAdes. LA BANALIDAD deL MAL EN LA CAJA 507}

La presencia del mal es uno de los rasgos constitutivos del cine negro; como afirma Carlos Heredero: "No hay ningún otro género en el cine clásico de Hollywood donde se pueda encontrar una concentración de malos por fotograma tan alta y tan densa" (1997: 51). José Antonio Hurtado entiende la presencia de la maldad en el cine negro como "comportamientos, acciones, actitudes y actividades, tanto individuales como colectivas, que conllevan un perjuicio, un daño, que implican una agresión y que se dan y se producen siempre en el ámbito de lo social" (2003: 242). Este apartado analiza la presencia de la maldad en La caja 507 a través de la fulminante mirada a la vida de una sociedad enferma en la que todos los niveles administrativos, policiales, jurídicos y mediáticos adolecen de una gravísima dejación de sus responsabilidades éticas y morales, sustituidas por la persecución del lucro económico como único motor existencial. El propio Urbizu explica su preferencia por el género en función de las posibilidades que ofrece para este cuestionamiento del sistema: "El negro es uno de los pocos géneros que nos permite acercarnos al funcionamiento del sistema, bien para justificarlo [...] bien para criticarlo, mostrando sus malas prácticas y sus elemento deficitarios para la comunidad" (Urbizu 2008: 218).

La caja 507 narra la historia de Modesto Pardo (Antonio Resines), un hombre sencillo (caracterizado como "un pobre hombre" por uno de los personajes), director de una pequeña sucursal bancaria en la Costa del Sol, que es víctima de 
un atraco y descubre por azar en unos documentos guardados en una de las cajas de seguridad, la 507, que el incendio en el que su hija murió unos años atrás fue provocado. Con su mujer en coma víctima de los atracadores y estos en fuga, decide vengarse. Su incursión en el mundo de la especulación inmobiliaria descubre la corrupción que impregna a todo el sistema y la presencia de una banda internacional de mafiosos para la que trabaja Rafael Mazas (José Coronado), un ex policía corrupto. La película se construye en un enloquecido avance paralelo que llevan a cabo estos dos hombres, cuyas marcadas diferencias se perciben ya en el simbolismo de sus nombres, como ya han señalado varios estudios (Herrero 2007; Sánchez Zapatero \& Marcos Ramos 2014). La inquietante y omnipresente caracterización de la sociedad como foco infectado por la corrupción va abriendo el foco e invadiendo espacios que comienzan en delitos tales como el robo y la intimidación y que progresan hasta una cadena de asesinatos en serie.

Esta lectura de la película propone partir de la profunda reflexión desarrollada hace más de medio siglo por Hannah Arendt en su obra Eichmann en Jerusalén, resultado de su labor como reportera enviada por la revista New Yorker para cubrir el juicio en 1961 en Israel a Adolf Eichman por genocidio contra el pueblo judío durante la Segunda Guerra Mundial. A pesar de la extraordinaria distancia que separa a lo sucedido en Alemania durante aquel tiempo de la realidad española de comienzos del siglo xxI, el término acuñado por Arendt la banalidad del mal es eficaz para explicar la maldad que exhibe el sistema en La caja 507. Al observar a Eichmann, el hombre que va ser juzgado, y que ha cometido los peores crímenes contra un número muy elevado de seres humanos, lo que advierte Arendt no es la maldad en el sentido de la perversión o el sadismo, sino algo más peligroso, que la autora denomina la banalización del mal y que define como la falta de pensamiento, la ausencia de reflexión ética hacia los demás y la normalización del comportamiento criminal. Lo que Arendt subraya es lo peligroso que resulta el comportamiento cuando el individuo no lleva a cabo un diálogo interno para examinar lo que sucede delante de sus ojos. La banalidad del mal que se revela a través de los ojos de Eichmann muestra la evidencia del modo absolutamente superficial en el que el mal puede desarrollarse y mostrar su cara más dañina y perjudicial. El mal se extiende cuando los ciudadanos no buscan el significado ético de las acciones. Afirma Arendt:

\begin{abstract}
El problema con Eichmann es, precisamente, que había muchos como él, y que no eran perversos ni sádicos sino que eran, y todavía son, terriblemente y terroríficamente normales. Desde el punto de vista de las instituciones legales y de nuestros criterios morales, esa normalidad es mucho más pavorosa que todas las atrocidades juntas. ${ }^{6}$ (Arendt 1994: 276)
\end{abstract}

\footnotetext{
6 "The trouble with Eichmann was precisely that so many were like him, and that the many were neither perverted nor sadistic, that they were, and still are, terribly and terrifyingly normal. From the viewpoint of our legal institutions and of our moral standards of judgment, this normality was much more terrifying than all the atrocities put together".
} 
Es obvio que las atrocidades que la película va desplegando no pueden ponerse en el mismo plano con los delitos y crímenes que proyecta una obra de ficción, pero el concepto es pertinente cuando se trata de observar el comportamiento de los personajes de la película. En primer lugar, todos los ambientes en La caja 507 están marcados, en mayor o menor escala, por un modo de actuación basado en la falsedad, la mentira y la desobediencia. En las primeras escenas de la película, María, la hija adolescente de Modesto Pardo, de diecisiete años, aparece fumando un porro en la ventana de su cuarto y preparando los preservativos que utilizará esa noche en el encuentro con su novio, mientras cuenta a sus padres que va a dormir a casa de una amiga. Si en el mundo de la mafia y de la delincuencia el modus operandi habitual es el chantaje y la extorsión (como hace Rafael Mazas con su adversario al mostrar unas fotografías de éste con muchachos menores de edad en Marrakesh), igualmente Modesto Pardo va aprendiendo que también en el mundo legítimo del Archivo Municipal ha de utilizar la mentira para conseguir su propósito. Ante la lentitud y la inoperancia del sistema inventa un inminente desahucio de su familia (con sus dos hijos inexistentes) para acelerar el proceso y conseguir así el dossier de la parcela de la finca de Las Zarzuelas, lugar en el que murió su hija tras el incendio provocado para lograr la recalificación del terreno y la subsiguiente construcción inmobiliaria.

Este es sólo el nivel más superficial del falseamiento, pero no es por ello insignificante, ya que supone el primer peldaño en la escala en la que todos los personajes participan de una manera caracterizada por la falta de reflexión hacia la existencia ética de la comunidad. Más allá de la falta de intención hacia el daño directo, afirma Arendt, la verdadera forma de entender la intención es la de considerarse a uno mismo como un ser político, cuya vida y cuyas reflexiones están indisolublemente ligadas a la vida y a los pensamientos de los otros. Por eso, lo "banal" no es más que el dejarse llevar por la falta de reflexión y en último término por la indiferencia. Por ello la "banalidad" del mal no debe en ningún caso entenderse como algo superficial o superfluo; muy al contrario, constituye la raíz del daño y del dolor más profundo. Tal vez el ejemplo más claro de esta formulación en la película se exponga en la escena en la que Modesto Pardo interroga a Santos Guijuelo, quien falseó el informe del incendio en su momento y cobró por ello. A las preguntas del protagonista: “Quién le ofreció tanto? ¿El alcalde? ¿Quién le dio el dinero?", Guijuelo responde mientras muestra la foto de su boda: "Lo consulté con ella. Lo pensamos mucho. Pero, ¿por qué no? Aquella chica ya estaba muerta. Yo había empezado a construir esta casa. Mi mujer no estaba bien". Paradójicamente, esa insistencia en el pensamiento -"Lo pensamos mucho"- lo que esconde es, precisamente, la carencia de una reflexión ética que, como señala Arendt, impediría la realización del delito. Las ventajas materiales que otorga la falsificación del documento deberían sopesarse en función de lo sucedido: la muerte de una joven, el dolor y el duelo de sus familiares y la destrucción del terreno a través de la especulación económica entre otros elementos. La actuación de Guijuelo se asocia a la normalidad ("cualquiera hubiera 
hecho lo mismo", parece decir) y la audiencia no puede dejar de preguntarse cómo hubiera actuado en una situación similar.

La sociedad de La caja 507 muestra un elevado nivel de corrupción en el que las acciones no están motivadas por la lógica de la actuación profesional, sino por una moral desplazada en la que se respetan las jerarquías por temor a las represalias. Así, cuando Pardo trata de filtrar la historia a Javier Landa, un reportero del diario local, éste inmediatamente lo consulta con su superior, quien alaba su decisión de consultarlo primero con él y asegura que él mismo se hará cargo del asunto, para inmediatamente hablar con el director general del periódico. Este, al conocer los nombres de los implicados en la trama, se muestra de acuerdo con el recelo de su subordinado hacia la exposición pública del caso, y afirma: "Has hecho muy bien, Ramón; creo que estoy de acuerdo contigo. Quizá es mejor que seamos discretos y no publiquemos nada". Empresarios, políticos, jueces y delincuentes se mueven bajo la misma motivación: la aspiración al enriquecimiento ilícito y el mantenimiento indiferente del sistema.

En un peldaño más alto de la misma escala se encuentra Rafael Mazas, jefe de la policía local, activamente implicado en el ocultamiento del incendio. Pardo consulta la hemeroteca y encuentra las portadas de los periódicos en las que se leen estos titulares: "Prevenir los incendios forestales es responsabilidad de todos" y "El jefe de policía Rafael Mazas afirma que la mayoría de los incendios forestales tienen su origen en accidentes fortuitos". Tales titulares son muestra, una vez más, de la normalización y de la falsificación del delito. Ninguno de los dos titulares pueden considerarse mentirosos y, sin embargo, esconden justamente la falta de sentido de la responsabilidad ética que el cargo de Mazas conlleva y la culpa extendida al azar, a lo fortuito o falto de causalidad, cuando no es sino el deseo imparable del enriquecimiento lo que motiva todos los actos. Cuando en las escenas finales se produce el encuentro cara a cara entre los adversarios, Pardo y Mazas, el primero aduce la razón por la cual el segundo se ve en este momento abocado a una muerte segura y recuerda el incendio. La respuesta de Mazas: "Eso. Eso fue un accidente" vuelve a retomar la noción de la banalidad del mal, asociada a la falta de reflexión responsable y a la preferencia por privilegiar la casualidad o el azar frente a la constatación del delito cometido.

En una película en la que la violencia está muy presente, pero cuya estética rehúye del regodeo en la contemplación de misma, y en la que los momentos de mayor violencia se adivinan más que se contemplan, el propio Urbizu proporciona pistas para la comprensión de su obra. Frente a la "hipervisibilización" de la violencia que percibe en películas recientes, el director desprecia el espectáculo de aturdimiento formalista y plantea un "sentido ético" de la existencia (2008: 220). Afirma Urbizu que La caja 507 es una película de gran dureza, pero que tal percepción viene motivada por lo que se cuenta y no por cómo se cuenta, y añade: "La caja 507 es una película contra la indiferencia más que contra la corrupción" (2008: 222). En efecto, la indiferencia y la falta de compromiso ético son las constantes que marcan la actuación de los habitantes de la película. Sánchez Zapatero y Marcos Ramos llevan a cabo un detallado análisis de la trama social ligada a los escándalos de la corrupción en la Costa del Sol (2014); baste 
ahora incidir en la escena en la que se anuncia el complejo inmobiliario Invierta aquí, emplazado en el lugar del incendio. El empresario a cargo del mismo, Don Gerardo de la Hoz, es descrito del siguiente modo por el presentador del acto (a quien ya hemos visto en anteriores escenas envuelto en la trama de corrupción): "Empresarios como nuestro ex alcalde y presidente, un hombre bajo cuya gestión modélica esta ciudad ha logrado alcanzar cotas envidiables de prosperidad, seguridad y futuro". Bajo este discurso retórico laudatorio se esconde, una vez más, otro eslabón del falseamiento y ocultación del incendio provocado. Cuando Pardo logra, por fin, a través de estrategias basadas en la amenaza y el chantaje, que la historia salga a la luz, uno de los titulares del periódico afirma: "Frágiles voluntades: El camino del dinero negro". La fragilidad de la voluntad, desvinculada del pensamiento ético responsable lleva a la negrura no solo del dinero, sino del tejido social y político.

Philip Zimbardo describe el mal en los sistemas administrativos como una presencia endémica y estructural, ya que va más allá del individuo una vez que los procedimientos instalados y las prácticas comunes se hacen constantes. Sin embargo, afirma: "Las instituciones deben tener líderes y esos líderes han de rendir cuentas por crear o mantener el mal [...]. Los individuos que desempeñan cargos de importancia en la creación de un sistema con prácticas ilegales y con una conducta inmoral y poco ética son responsables a pesar de las presiones que puedan recibir"7 (2007: 438). En La caja 507 esas "frágiles voluntades" no son castigadas por el sistema y la indiferencia general reina en un sistema en el que la corrupción parece reinar a su antojo. En ese medio, es la actuación individual de Modesto Pardo, que aprende a moverse como pez en el agua en los métodos asociados al chantaje y a la extorsión empleados para lograr su propósito, la única que resulta efectiva para destapar y combatir el mal. A pesar de que finalmente él también busca y obtiene el mismo fin, que no es otro que el dinero, su situación como padre que ha perdido a su hija y ha estado a punto de perder a su mujer y su habilidad para manipular el sistema despiertan las simpatías de la audiencia, que se alegra de éxito. No obstante, la película concluye con una breve escena en la que Pardo habla con su mujer, que se recupera en un lujoso balneario, y es posible advertir cierto reproche en las palabras que esta le dirige aludiendo a su nuevo vestuario y a su intención de comprar un coche caro. La última frase de la película, que pronuncia Modesto: "Bueno, he cambiado" culmina el proceso que ha transformado al protagonista en superviviente avezado en el mundo del mal. Como apuntan Marcos Ramos y Sánchez Zapatero (2015) la escena apunta a la mirada desoladora que la película proyecta sobre la sociedad, interpretada como un sistema degradado capaz de corromper incluso a seres tan aparentemente honestos como Modesto.

\footnotetext{
7 "Nevertheless, I would argue, organizations must have leaders, and those leaders must be held accountable for creating or maintaining such evil [...]. The individuals who play key roles in creating a system that engages in illegal, immoral, and unethical conduct should be held accountable despite the situational pressures on them".
} 


\section{No habRá PAZ PARA lOS MALVADOS. El MAL EN LA SOCIEDAD LÍQUidA ACTUAL ${ }^{8}$}

En la película dirigida por Urbizu en 2011 es posible advertir una nueva formulación del mal que pervive y se extiende en las sociedades actuales. Para su comprensión resulta de utilidad acudir a la concepción del mal elaborada por Jean Baudrillard en su ensayo titulado "La transparencia del mal". Entiende el pensador francés que vivimos en una sociedad que ha tratado artificialmente de extirpar el mal hasta tal punto que éste resurge en las formas virales y terroristas contemporáneas que conocemos:

En una sociedad que a fuerza de profilaxis, de eliminación de sus referencias naturales, de blanqueamiento de la violencia, de exterminio de sus gérmenes y de todas las partes malditas, de cirugía estética de lo negativo, sólo quiere vérselas con la gestión calculada y con el discurso del Bien; en una sociedad donde ya no existe ninguna posibilidad de nombrar el Mal, éste se ha metamorfoseado en todas las formas virales y terroristas que nos obsesionan. (Baudrillard 1991: 90)

Añade Baudrillard que tal deseo de expulsar de nosotros la parte maldita nos ha vuelto vulnerables al menor ataque, y caracteriza el principio del Mal como la energía de la parte maldita. El mal en la película de Urbizu está encarnado en los grupos terroristas de las células yihadistas radicales, que se proponen realizar una matanza al estilo del 11-M mediante la colocación de bombas camufladas en los extintores de un centro comercial. El propio Urbizu afirma que la película en su génesis tiene una clara intención de responder a las preguntas de cómo es posible que pasen cosas como lo del 11-M, qué es lo que no funciona bien en la gestión de nuestra seguridad y qué mecanismos siguen ciertas tramas delictivas (Urbizu 2015). Santos Trinidad, el protagonista a quien da vida José Coronado será un inspector de policía que impide que se lleve a cabo el atentado; la premisa que sugiere este trabajo es que la energía del mal, encarnada en este terrorismo contemporáneo, es compartida en un alto grado por el propio protagonista, que no renuncia en ningún terreno -ni en el fisiológico, no en el psicológico ni en el moral- al mantenimiento del mal en su persona, lo que le provee de los rasgos esenciales para hacer frente a los malvados con sus mismas armas de actuación.

La juez Chacón y su ayudante Leiva son la representación de los intentos del Bien para llevar adelante un trabajo meticuloso, arduo y responsable que permita identificar y combatir la energía del mal. Sin embargo, en la película al igual que sucede en las sociedades contemporáneas, quienes han de combatir estas nuevas formas de terrorismo se ven caracterizados por la ineficacia y la lentitud, frente a la capacidad de actuación y a la velocidad con la que se mueve el mal. En la película y en la sociedad madrileña, como afirma Zygmunt Bauman, la maquinaria Estado-nación, que anteriormente podía separar claramente a los de dentro de los de fuera (énfasis en el original) y así proteger la soberanía terri-

${ }^{8}$ Para una versión anterior de este apartado, véase Rodríguez (2013). 
torial, "ha sido tomada de improviso por la nueva interconexión total del planeta" (2007: 162, énfasis en el original), y añade Bauman: "Día tras día, con una atrocidad terrorista tras otra, las instituciones legales y de orden público del Estado se dan cada vez más cuenta de su propia ineptitud para manejar esos nuevos peligros que tan ostensiblemente acaban echando por tierra las viejos y consagradas (y, hasta hace poco, fiables) categorías y distinciones ortodoxas" (2007: 162). En estos tiempos líquidos, como afirma Bauman, "los peligros y los miedos tiene también consistencia líquida [...]. Fluyen, calan, se filtran rezuman" y concluye "El fantasma de la vulnerabilidad planea sobre el planeta negativamente globalizado" (2007: 127). En este sentido afirma Urbizu:

Creo que vamos absolutamente a la deriva, hay muchísima incertidumbre, muchísimo miedo social. Ya no sabemos qué valores abrazar, o tienes pasta o estás perdido. Creo que el movimiento $15-\mathrm{M}$ es un baremo perfecto de lo que pasa, ha surgido una pregunta aterradora: ¿quién manda? Los gobiernos elegidos democráticamente empiezan a no pintar nada. Estamos viviendo una época aterradora. (Urbizu en Arce 2011)

En la película, la juez Chacón lleva adelante el tipo de trama característica del cine negro denominada police procedural que muestra a la audiencia el proceso detallado de la investigación: el seguimiento de pistas, los interrogatorios, las pruebas balísticas y forenses, etc. Chacón despierta una inmediata identificación positiva en la audiencia: su aspecto impecable, su tenacidad y su ética del trabajo son incuestionables. Se afana por utilizar todos los recursos legales para combatir el mal. Sin embargo, la película juega continuamente por medio de procedimientos narrativos y visuales con esa idea de la ineficacia endémica contra las formas modernas de terrorismo que propone Bauman. En su primera aparición en pantalla la vemos aplicándose un colirio ocular atrapada en un atasco, lo que le hará llegar tarde al lugar de los hechos. Se emplaza a este personaje, por tanto, en un medio en el que no funciona adecuadamente ni en los parámetros visuales ni en los temporales. Al llegar a la escena del crimen, pregunta: "¿Y este olor?", a lo que responde Leiva: "Estos sitios huelen así, señoría", con lo que de nuevo se acrecienta su falta de conocimiento del medio (un club de alterne), esta vez a través del olfato. De modo similar, cuando la juez debe reunirse con un alto cargo de la policía que llevó a cabo investigaciones relacionadas con el caso en el pasado, éste se disculpa del siguiente modo: "Disculpe que la haya hecho venir aquí pero con esto de la Cumbre estamos todos fuera de sitio". Tal afirmación podría tal vez extenderse metonímicamente a la totalidad de los cuerpos policiales, emplazados fuera de sitio o tardíamente situados en los escenarios del crimen. Los esfuerzos denodados de Chacón por llevar adelante la investigación y su profesionalidad se enfrentan a una farragosa y desmedida burocracia policial y no son suficientes en un complejo panorama de delincuencia que va desde las guerrillas colombianas de las FARC y el tráfico de cocaína hasta la venta de hachís proveniente de Marruecos ligada a las actividades islamistas radicales. Esa presencia del mal en No habrá paz para los malvados responde admirablemente a la caracterización que lleva a cabo Baudrillard: 
Bajo la transparencia del consenso está la opacidad del mal, su tenacidad, su obsesión, su irreductibilidad, su energía inversa trabajando por doquier en el desarreglo de las cosas, en la viralidad, en la aceleración, en el desbocamiento de los efectos, en la superación de las causas, en el exceso y la paradoja, en la extrañeza radical, en los atractores extraños y en los encadenamientos inarticulados. (Baudrillard 1991: 115-16)

El comisario con quien Chacón trata infructuosamente de seguir la pista a quien será el cabecilla del ataque terrorista, continuamente hace alusión a la imposibilidad de concluir las investigaciones, ya que, afirma, se mueven muy rápidamente, se desplazan continuamente de uno a otro lugar y en esa aceleración obstinada en ese desarreglo de las cosas se basa su capacidad de actuación.

Frente a ese cuerpo policial y judicial caracterizado físicamente por la sobriedad y la pulcritud en sus formas y en sus líneas aparece el cuerpo en progresiva descomposición del inspector Santos Trinidad, único capaz en último término -como anuncia su nombre de carácter redentor- de salvar a la ciudad y a la nación de un atentado masivo. Santos Trinidad es una mezcla de cowboy, inspector de policía de estética setentera, samurai o, en las palabras de Urbizu: "Este va como un zombi en línea recta, no tiene salvación posible" (Urbizu en Arce 2011). Contrario por completo a esa profilaxis y exterminio de partes malditas, a esa cirugía estética de lo negativo que describe Baudrillard, Santos Trinidad se dedica con ahínco a destruir su cuerpo mediante la ingesta feroz de ron y cigarrillos; su físico está marcado por la decadencia y la falta de adecuación a los tiempos que corren, pero no está exento, sin embargo, de cierto poder de seducción. En palabras de Urbizu: "José tiene un físico que se puede permitir este deterioro, anclado dos décadas atrás, sin perder la postura, sigue siendo un bicho que te apetece mirar" (Urbizo en Arce 2011). Los sucesivos apuñalamientos que sufre el protagonista -en lugar de recibir tiros o puñetazos- acentúan la naturaleza de ese cuerpo que se rompe y se desangra, que va perdiendo su consistencia física por medio de la descomposición interna y externa. Su emplazamiento en la pantalla se sitúa frecuentemente en los extremos, como apunta Manu Argüelles (2011): "siempre vagará por el film como un fantasma, siempre al borde del precipicio (no es casual que su colocación espacial natural en los planos sea en los extremos del marco), evidenciando una tensa expresividad corporal fruto de la violencia interiorizada que le arde en su seno".

La violencia extrema que exhibe el protagonista en las escenas iniciales de la película participa de la caracterización de la energía del mal de Baudrillard en su exceso y extrañeza radical, en el encadenamiento inarticulado que suponen esos tres asesinatos a quemarropa sin que podamos saber, ni siquiera al final,

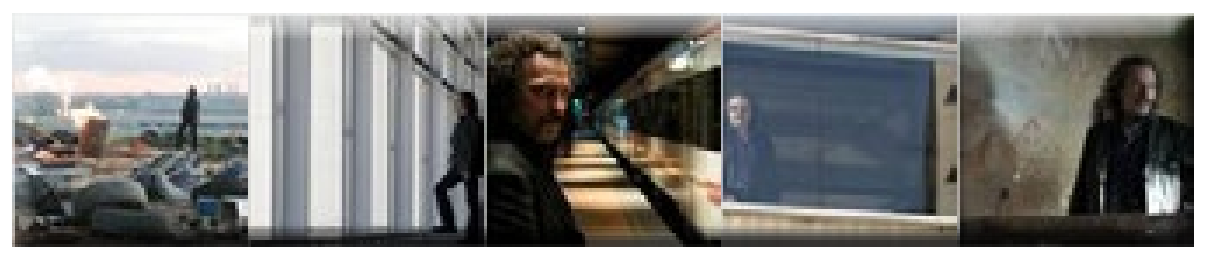

150 Pasavento. Revista de Estudios Hispánicos, vol. IV, n. ${ }^{1}$ (invierno 2016), pp. 139-155, ISSN: 2255-4505 
si responden a un alto grado de borrachera, a un ajuste de cuentas motivado por los recuerdos de su pasado en su destino en la embajada en Colombia, o a un episodio con alguna relación con la trama principal del proyectado ataque terrorista. Sus escasísimos diálogos confluyen en una similar tendencia a la destrucción: "A tomar por culo el mundo", comenta a su compañero de vigilancia en la policía, o "A tomar por culo", contesta cuando su jefe le pregunta a dónde se dirige. A pesar de todo ello, disminuidas sus facultades por ese consumo constante de alcohol -a cualquier hora del día o de la noche- e incluso por la heridas, Santos Trinidad siempre llega antes a los sitios, siempre va un paso por delante, consigue las pruebas y las evidencias antes que los representantes institucionales del bien y es capaz de atar cabos hasta descubrir el plan de ataque terrorista.

Durante la mayor parte de la trama la audiencia observa el desarrollo de las dos líneas paralelas de investigación y hasta que no empiezan a confluir el protagonista va logrando pisar el terreno tanto a los terroristas como a la juez. Su exclamación al descubrir al cabecilla de la banda ("El Ceutí") en plena operación en el centro de Madrid cuanto todos creen que está en Londres: "Rock and roll" vuelve a dar fe de esa energía que mueve al personaje y que le permite ver más allá de esa apariencia y simulacro de orden y falsa seguridad que ofrece la ciudad. En las prácticas de tiro en las que dispara junto a su compañero, éste le recrimina: "Estás perdiendo facultades", a lo que Trinidad responde: "Esos son muñecos", aludiendo de nuevo al fondo tras la apariencia, a su habilidad para romper el simulacro y convertirse en verdugo real.

Poco o nada sabemos del pasado del protagonista hasta el momento esencial en la película en la que comienzan a confluir esas dos líneas de procedimiento policial cuando Leiva comienza a sospechar de la involucración de Trinidad en el caso que investigan. Las dos declaraciones de la juez Chacón antes y después del interrogatorio al que le somete reproducen adecuadamente la ignorancia y la perplejidad de la audiencia en este momento. Si antes de verse las caras con él se pregunta: "Pero, ¿qué significa? ¿Éste qué tiene que ver con los colombianos?", tras la entrevista afirma: "No entiendo cómo este personaje puede estar todavía en la policía". En el transcurso del interrogatorio conocemos algo del pasado de Trinidad y su trayectoria desde sus ejemplares comienzos en el cuerpo (primero de su promoción, Gran Orden del Mérito Policial, grupos especiales de operaciones) hasta sus progresivos problemas con el alcohol y de índole psiquiátrica junto con la muerte de un hombre (en acto de servicio, aclara él). La última apreciación de la juez claramente enuncia la falta de adecuación de alguien como Santos Trinidad en las asépticas filas del bien y del orden. Así describe Manu Argüelles (2011) las posiciones de los dos: "Uno insertado en la violencia y en el cuerpo social putrefacto, la otra desde la vía administrativa y desde la quirúrgica distancia". Por ello, la puesta en escena que la acompaña opta por el plano de líneas firmes, una matemática serena y sobria, que contrasta con los colores fuertes y las expresiones abruptas del entorno de Santos.

A partir de este momento será más fácil seguir la pista a Santos Trinidad, ya identificada su presencia en la trama hasta el momento final. Este recupera el aspecto de cowboy que caracterizaba su primera aparición en las últimas 
escenas en las que logra dar muerte a los cabecillas de la banda terrorista y desmantelar el plan de hacer estallar las bombas camufladas en los extintores en el centro comercial Islazul. Este centro comercial está marcado visualmente por la armonía, la luminosidad y la seguridad, tan falsa como las palmeras que pretenden dotar al emplazamiento de un carácter natural y hasta tropical. La amenaza latente se hace explícita en los últimos planos de la película, en la que van apareciendo las figuras humanas en el paisaje vacío del centro comercial junto a cada uno de los extintores.

¿Cuál es la lectura última de No habrá paz para los malvados a través de las líneas de las presencias líquidas del mal? Una primera -y lícita lectura- resulta cuanto menos inquietante: frente a la incapacidad de las fuerzas y cuerpos de seguridad del Estado para combatir las nuevas amenazas terroristas, solo puede alcanzarse la salvación por medio de la intervención individual de alguien dispuesto a saltarse las normas y a combatir al enemigo con sus mismas y violentas armas. A ello cabría incluso sumar una lectura preocupante en relación a la identificación de todos los males con los colombianos y los islamistas presentes en la ciudad (tráfico de drogas, violencia y masacres en masa y hasta sexismo inherente, que lleva a una familia madrileña a perder a su hija perfectamente educada en la igualdad en el encierro que le impone su esposo, que no es otro que El Ceutí). Sin desdeñar estas apreciaciones, importa situar la película de Urbizu en las coordinadas del cine negro; como señala José Antonio Hurtado, en este género se arroja sobre el gánster una mirada moralizante y se insiste, sobre todo, en su condición de enemigo público que hay que erradicar (2003: 248-9), y tal es la función de estas nuevas proyecciones de los malvados en la película. Es apropiado igualmente considerar la noción expuesta por Santiago González Escudero -no en relación a esta película, sino a la presencia del mal en el cine en general- cuando afirma que el mal constituye un sustantivo extraño puesto que difícilmente puede ser señalado, definido o localizado salvo cuando ya ha producido sus efectos y únicamente se hace posible a través de su transmisión (2003: 195). En este caso la transmisión se hace posible por medio del plano que traslada las miradas de la juez Chacón y de Leiva sobre los cuerpos muertos de los terroristas y del protagonista en la última escena; los vivos -al fin y al cabofrente a los muertos. Si bien Trinidad logra que el mal no pueda producirse y evita su localización, los que sobreviven son los responsables de mantener la seguridad y el orden, que ahora deben replantearse las apreciaciones anteriormente formuladas en cuanto a la idoneidad de la pertenencia del protagonista al cuerpo policial. Creo, por ello, que la película propone una cierta reivindicación de la inmersión en las coordenadas líquidas del mal para actuar con la energía y la velocidad que caracteriza a estas nuevas encarnaciones en sus modos fugaces de operar. Rechaza la visión aséptica y quirúrgica de un Bien profiláctico y desprovisto de la posibilidad de entender el Mal, de aceptarlo y de incorporarlo a la experiencia social contemporánea. Las excesivas y dicotómicas distancias que la película exhibe entre el escenario visual de la preparación de la Cumbre del G-20 -caracterizado por el lujo y la vigilancia extrema- y los páramos de los polígonos industriales donde se gesta la preparación del ataque terrorista o los 
basureros abandonados, igualmente llaman nuestra atención sobre una ciudad de espacios marcados por la desigualdad. El acceso a estos últimos solo está permitido a aquellos que, como Santos Trinidad, son capaces de adentrarse en sus entrañas y finalmente, de mostrar sus entrañas abiertas a la mirada enmudecida de los guardianes de la ley, para quienes quedan abiertas -al igual que para la audiencia- preguntas y reflexiones para el futuro.

\section{CONCLUSIÓN}

Urbizu ha aludido en numerosas ocasiones a su deseo de hacer un cine negro comprometido y éticamente ligado a su entorno: "Por eso intento que mi cine dé claves del mundo en que vivimos, porque considero que mostrar la podredumbre moral y el mal funcionamiento del sistema es parte de mis obligaciones como director de cine y como ciudadano" (2008: 229). Urbizu expone un sistema corrupto en el que solo los individuos con una determinación descomunal pueden hacer frente al mal, aunque sea pagando el precio de la auto inmolación. Philip Zimbardo, a partir de la formulación de Arendt, contrasta la "banalidad del mal" con la "banalidad del heroismo", término mediante el cual hace referencia al modo en el que un individuo cualquiera puede alzarse por encima de las presiones y las dificultades en un sistema marcado por el mal y ejercer una actuación en defensa de la dignidad humana (2007). Modesto Pardo y Santos Trinidad son y no son héroes, pero no cabe duda de que sus acciones individuales son las únicas que logran desmantelar los males del sistema social e intervenir eficazmente para transformar la apatía, la indiferencia y el peligro inminente. A pesar de que en ninguno de los dos casos ofrecen modelos ejemplares de comportamiento y de que ambos protagonistas se valen de las mismas armas que sus enemigos (el chantaje y la violencia) para lograr sus objetivos, no es menos cierto que las películas proponen una identificación positiva con ellos por parte de la audiencia, que los ve como los únicos elementos de ajuste ético en un sistema social enfermo y amenazado. La presencia de figuras como Michel Gaztambide como co-guionista junto al director y de José Coronado como protagonista en ambas películas proporciona una continuidad en la forma y en el sentido de la cinematografía de Urbizu, que se ha ido configurando como el mejor representante de un género negro comprometido de gran atractivo visual que logra mantener el suspense a través de unos guiones impecablemente elaborados y de unas magníficas actuaciones.

\section{OBRAS CITADAS}

Alarcón, Tonio (2011): "Enrique Urbizu: el género como figura de estilo", Dirigido por. Revista de Cine, n. ${ }^{\circ} 415$, pp. 42-49.

Arce, José (2011): “Enrique Urbizu, director de No habrá paz para los malvados: Vivimos una época aterradora", <http://noticias.labutaca.net/enrique-urbizu-director-de-no- 
habra-paz-para-los-malvados-vivimos-una-epoca-aterradora/> [última consulta: 15.05.2015].

Argüelles, Manu (2011): "A la caza. No habrá paz para los malvados", <http://www.elespectadorimaginario.com/pages/octubre-2011/criticas/no-habra-paz-para-los-malvados.php> [última consulta: 27.05.2015].

Arendt, Hannah (1994): Eichmann in Jerusalem: A report on the banality of evil. Nueva York, Pneguin.

Baudrillard, Jean (1991): La transparencia del mal. Ensayo sobre los fenómenos extremos. Barcelona, Anagrama.

Bauman, Zygmunt (2007): Miedo líquido. Barcelona, Paidós.

Davies, Ann (2007): "Spanish Neo-Noir". En Andrew Spicer (ed.): European Film Noir. Manchester, Manchester UP, pp. 210-35.

Heredero, Carlos (1997): "Cuando la sustancia es el mal. Gánsteres, criminales y mujeres fatales en el cine negro", Academia, 18, abril.

Heredero, Carlos, y Santamarina, Antonio (2003): Enrique Urbizu. La imagen esencial. San Sebastián, Filmoteca Vasca.

Herrero, Carmen (2007): "Paisajes urbanos y 'no lugares' en el thriller español contemporáneo: Fausto 5.0 y La caja 507", Romance Studies, vol. 25, n. ${ }^{\circ} 2$, pp. 137-149.

Hurtado, José Antonio (2003): "Sombras de sospecha (Notas sobre la maldad en el cine negro)". En Vicente Domínguez (coord.): Imágenes del mal. Ensayos de cine, filosofía y literatura sobre la maldad. Madrid, Valdemar, pp. 239-255.

González, Santiago (2003): "Las raíces del mal. El esquema de Platón". En Vicente Domínguez (coord.): Imágenes del mal. Ensayos de cine, filosofía y literatura sobre la maldad. Madrid, Valdemar, pp. 179-206.

Medina, Elena (2000): Cine negro y policíaco español de los años cincuenta. Barcelona, Laertes.

Mira, Alberto (2000): "Transformations of the Urban Landscape in Spanish Film Noir". En Myrto Konstantarakos (ed.): Spaces in European Cinema. Exeter, Intellect, pp. 124-37.

Rodríguez, María Pilar (2013): "No habrá paz para los malvados. Presencias líquidas del mal". En: Historia, memoria y sociedad en el género negro. Literatura, cine, televisión y cómic. Santiago de Compostela, Andavira, pp. 389-395.

Sánchez Barba, Francesc (2007): Brumas del Franquismo. El auge del cine negro español (1950-1965). Barcelona, Universitat de Barcelona.

Sánchez Zapatero, Javier, y Marcos Ramos, María (2014): "La representación de la sociedad en el cine negro: Enrique Urbizu y La caja 507", Tonos digital, n. ${ }^{\circ} 27$. Disponible en <https://digitum.um.es/xmlui/bitstream/10201/40433/1/La\%20 representaci\%C3\%B3n\%20de\%20la\%20sociedad\%20en\%20el\%20cine\%20negro. pdf> [última consulta: 26.05.2015].

— (2015): "La consolidación de un género: el cine negro español", Cuadernos de ALDEEU. Número especial: Cine español y latinoamericano, n. ${ }^{\circ} 29$, pp. 32-58.

Schrader, Paul (1996): "Notes on Film Noir". En Adam Silver y James Ursini (eds.): Film Noir Reader. Nueva York, Limelight, pp. 53-63.

Spicer, Andrew (2010): Historical Dictionary of Film Noir. Plymouth, The Scarecrow Press. 
Stone, Rob (2007): "Spanish Film Noir". En Andrew Spicer (ed.): European Film Noir. Manchester, Manchester UP, pp.185-209.

Urbizu, Enrique (2008): "Delito, violencia y puesta en escena". En Àlex Martín Escribà y Javier Sánchez Zapatero (eds.): Palabras que matan: Asesinos y violencia en la ficción criminal. Córdoba, Almuzara, pp. 217-229.

— (2011): Entrevista a Enrique Urbizu. Universidad Carlos III (Getafe), 5 de octubre. Disponible en <http://www.youtube.com/watch?v=ONLE-9LHQRg> [última consulta: 9.05.2015]

Zimbardo, Philip (2007): The Lucifer Effect. Understanding how good people turn evil. Nueva York, Random House. 